\title{
Two males, one female: triplet-style mating behaviour in the Darwin wasp Xorides ater (Gravenhorst, 1829) (Hymenoptera, Ichneumonidae, Xoridinae) in the Swiss Alps
}

\author{
Mark R. Shaw ${ }^{1}$, Madalene Giannotta ${ }^{2,3}$, Andrés F. Herrera-Flórez ${ }^{4}$, Seraina Klopfstein ${ }^{5}$ \\ 1 National Museums Scotland, Department of Natural Sciences, Edinburgh EH1 1JF, Scotland \\ 2 Research School of Biology, The Australian National University, Acton ACT 2601, Australia \\ 3 Australian National Insect Collection, National Research Collections of Australia, CSIRO, Canberra, ACT 2601, Australia \\ 4 Friedrich-Schiller-Universität Jena, Jena, Germany \\ 5 Naturhistorisches Museum Basel, BIO, Augustinergasse 2, 4051 Basel, Switzerland \\ http://zoobank.org/EFABDF47-8EA3-4BE7-80E1-692B55112137
}

Corresponding author: Seraina Klopfstein (seraina.klopfstein@bs.ch)

Academic editor: Andreas Müller • Received 22 February 2021 • Accepted 20 April 2021 • Published 21 May 2021

\begin{abstract}
The Darwin wasp Xorides ater is a solitary idiobiont ectoparasitoid of wood-boring beetle larvae. It occurs across the Palaearctic, and in Switzerland seems to be restricted to areas above $980 \mathrm{~m}$ altitude. Very little is known about its biology and behaviour. We here report three separate instances of a female $X$. ater mating simultaneously with two males, observed on the same occasion on a Picea abies woodpile near Lenk, Switzerland. Only two copulae that involved one male and one female were observed at the same time, which might indicate that this mating mode is rather common in $X$. ater. We illustrate our observations with photo and video material and compare it to mating behaviour known from other species of Darwin wasps.
\end{abstract}

\section{Key Words}

Altitudinal distribution, Copulation stance, Phenology

\section{Introduction}

Hymenoptera have a haplo-diploid reproductive mode (Crozier 1975) and, although thelytoky is not uncommon in the order, most species reproduce sexually through union between a haploid male and a diploid female. The latter then lays eggs that are either haploid (male-producing) or diploid (female-producing) through her ability to control access of sperm to the egg as it passes down the oviduct and past the spermatheca (Gerber and Klostermeyer 1970; Cole 1981; Strand 1989). Female hymenopterans are thus able to produce viable offspring without having to mate, although the offspring then would only be of the male sex. This mode of sex determination, known also as arrhenotokous parthenogenesis, is believed to have had a great bearing on the success of the order (Gauld and
Bolton 1988; Heimpel and De Boer 2008). It is especially through the ability of mated females to control the sex of the eggs they lay that the ensuing complex behavioural and evolutionary ecology of parasitoid Hymenoptera has been so well-studied, albeit in a very limited number of species (Godfray 1994; Wajnberg et al. 2008).

Detailed courtship studies have been made only in a minute fraction of Darwin wasp species, but it is usual for female parasitoid Hymenoptera to be receptive to mating for only a short time following their emergence (Quicke 1997). Courtship is typically rather brief but can involve elaborate cues. It is usually initiated by volatile pheromones emanating from females (Quicke 1997; McClure et al. 2007) and may then involve wing-fanning "songs" (Bredlau and Kester 2019), male-male struggles over access to females (Eggleton 1991), or the transfer of contact 
pheromones from the antennae of the male to those of the female (Steiner et al. 2010).

It is by no means unusual for several males of a range of parasitoid wasps to simultaneously court a female, and aggregations of competing males are commonly observed, especially in parasitoids of wood-boring insect larvae such as Pimplinae (Theronia maculosa Kreiger, 1906, M. Giannota observations) and Rhyssinae (Eggleton 1991). However, to the best of our knowledge, only a single male has ever been observed to achieve copulation at any one time, even though females are sometimes receptive to repeated matings with the same or a different male for a short time afterwards (Quicke 2015; M. R. Shaw observations). With the exception of a very brief mention of Rhyssa persuasoria Linnaeus, 1758 being observed with two males apparently attached, though this was under conditions of disturbance whereby a large courting aggregation was being deliberately dismantled (Baker 1992), we have not encountered reports of more than one male achieving simultaneous copulation (whether ejaculation or not) with a single female in any species of Ichneumonoidea. We have never observed it ourselves during many decades of extensive rearing and field observations and, on that basis, we presume that it is highly unusual for it to occur.

It was therefore a surprise to observe three instances of a female of the xoridine ichneumonid Xorides ater Gravenhorst, 1829 in copula with two males, and apparently comfortably so for a prolonged time. During the same observation period, we observed only two standard pairings in the same location. In this brief report, we describe and illustrate these observations.

\section{Study species}

Xorides ater (Fig. 1) is a member of the putative sister group to all other Darwin wasps, the subfamily Xoridinae (Klopfstein et al. 2019; Bennett et al. 2019). By analogy with congeners $X$. brachylabis Kriechbaumer, 1889 and X. irrigator Fabricius, 1793 (Chrystal and Skinner 1931), and $X$. corcyrensis Kriechbaumer, 1894 (Sharifi and Javadi 1971), X. ater can safely be presumed to be an idiobiont parasitoid (i.e., one that kills or permanently paralyses its host at the time of oviposition) whose solitary larva develops on the body of its beetle larva, prepupa or pupa host. The parasitoid would pass the winter in its cocoon; however, neither the host range nor the developmental biology of $X$. ater is properly understood, nor is there any report of its courtship and mating behaviour.

\section{Materials and methods}

\section{Circumstances of observations}

During a period of general collecting of Ichneumonoidea near Lenk in the Swiss Canton of Bern, we came across an exposed woodpile of cut and partly split spruce logs
(Picea abies), originally up to about $20 \mathrm{~cm}$ diameter before being split. The woodpile was located just below Läheweid, about $600 \mathrm{~m} \mathrm{NW}$ of the cable car station Bettelberg, Stoos $\left(46^{\circ} 26^{\prime} 40^{\prime \prime} \mathrm{N}, 7^{\circ} 25^{\prime} 31^{\prime \prime E}\right)$ at about $1510 \mathrm{~m}$ altitude. The observations took place on 3.vii.2019 in the early afternoon from $13.00 \mathrm{hrs}$ to $15.00 \mathrm{hrs}$ of a humid and intermittently sunny day. The dimensions of the woodpile, which had a corrugated iron cover, was approximately $10 \times 2 \times 1 \mathrm{~m}$ and ran length-ways from West to East with one side in shade (at $23{ }^{\circ} \mathrm{C}$ ) and with the majority of insect activity observed on the shaded side. From the insect species seen on the woodpile and their activity, we deduced that it had been present for at least two years.

Photographs and short video recordings were taken with an Olympus EM-5 Mark II with a $60 \mathrm{~mm}$ macro-Olympus lens and later viewed and processed in Adobe Photoshop 2020 and Adobe Illustrator 2020. The composite video was edited in iMovie 10.2.3.

\section{Results}

\section{Activity and mating observations}

Arriving at the woodpile, we immediately observed a very high level of Ichneumonoidea activity, at one point counting more than 40 males in flight in front of the shaded side of the woodpile. Not only males but also females were present, and closer examination revealed that most of the individuals belonged to the ichneumonid $X$. ater (Fig. 1) with fewer of the similarly sized (but koinobiont endoparasitoid) braconid Helcon nunciator Fabricius, 1793. At least some of the females of $X$. ater present were clearly freshly emerged, as matings were occurring, though there were also some females resting without being courted that may or may not have already mated. A few males of $X$. ater were observed at rest but more often they were flying close to the woodpile and apparently in search of females, although without evident aggregation. Although some adult parasitoids were seen on the sunny (southern) side of the woodpile, insects there were too highly active to be easily observed or collected, and most of our observations were made on the shaded (northern) side, where insects were more abundant and easier to observe.

In the braconid $H$. nunciator, we observed about three matings, each between one male and one female. In $X$. ater, on the other hand, over a period of about two hours we saw three instances of a female $X$. ater with two males attached in apparent mating mode (Fig. 2A, B; Suppl. material 1: Movie 1). Only two copulations involving a single individual of each sex by this species were observed during the same period (Fig. 2C, D; Suppl. material 1: Movie 1). Unfortunately, no courtships or commencements of copulation were seen, so whether the attachment of the two males in the triplets happens simultaneously or sequentially is unknown.

In addition to the fact that the triplet-style matings appeared to happen rather easily and possibly even 


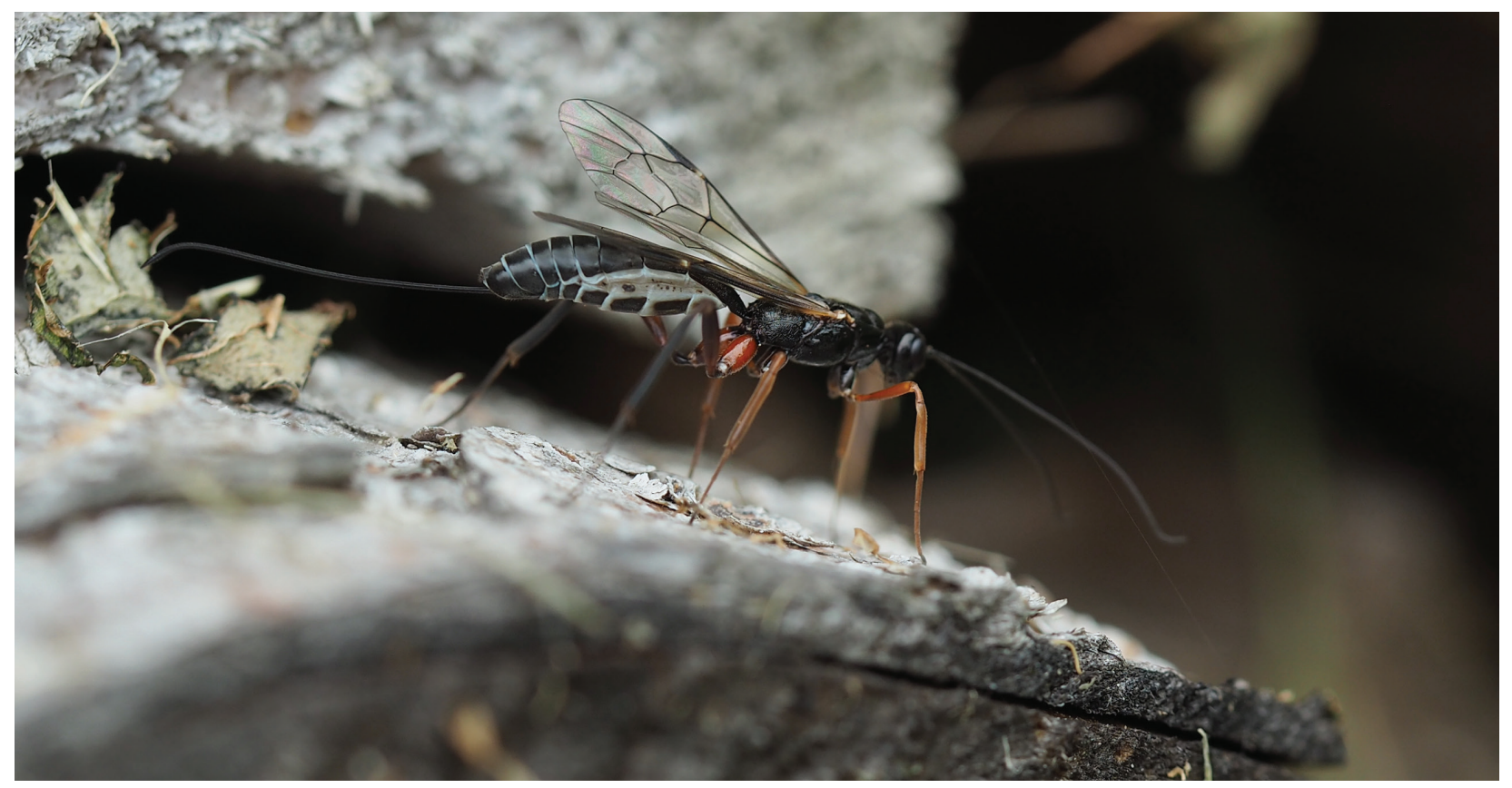

Figure 1. Xorides ater female. Freshly eclosed female resting on a Picea abies woodpile in the Swiss Canton of Bern.
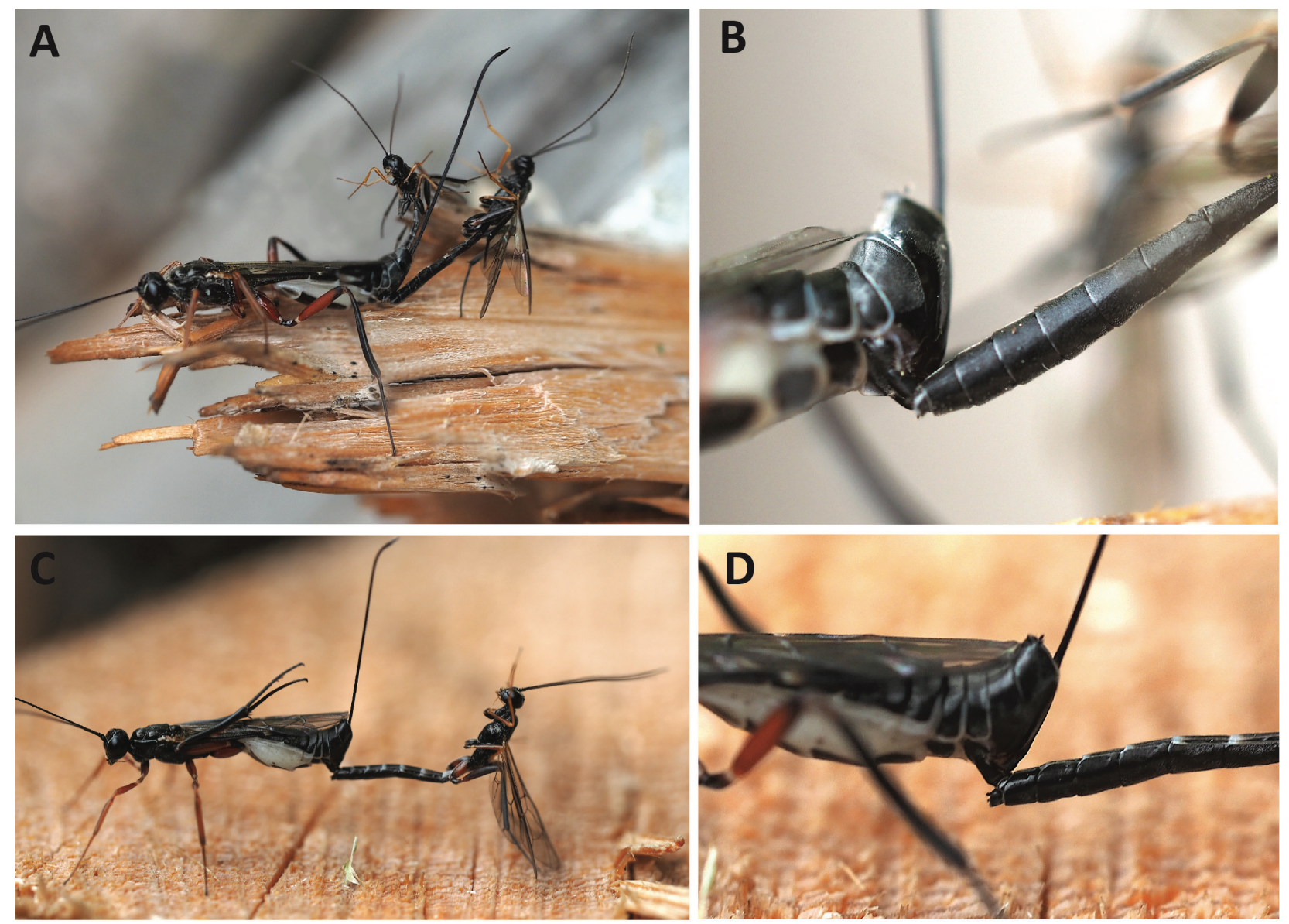

Figure 2. Xorides ater mating behaviour A Adult female (left) in copula with two attached males (right). [For greater clarity, figure 2A has been edited to create a stacked composite image of two less-focused images. The original raw files are available in Suppl. material 2: S.Fig. 1A and S.Fig. 1B]; B Close up of genitalic attachment points - left paramere of male (right) attached to the sixth sternite of female (left). Parameres of second male (background) are obscured from view; C Adult female (left) in copula with single male (right). Only the hind legs of the male are in contact with the wood; D Close up of genitalic attachment points - left paramere of male (right) attached to the sixth sternite of female (left). 
regularly, several things struck us. In the first place, the union seemed to be satisfying all three participants as, overall, the assemblages were as quiescent as the two normal copulae seen at the same time and appeared to persist for an equivalent period (at least 5-10 minutes, with separation occurring only as we collected them). Second, there was no evident jostling or attempt by one male to dislodge the other; indeed, they seemed extremely relaxed, with legs twitching and often held outstretched and clear of everything (usually at least one hind leg touched the substrate, but sometimes all legs were completely free). The females, too, seemed unperturbed and made no attempt to dislodge either male. Third, the positioning of the genitalia appeared to be normal, although the precise mechanism of attachment of males to the female's sixth sternite (hypopygium) in the triplets could not be investigated in any detail. However, the single paramere (= harpe, sensu Schulmeister 2001) that was visible appeared to be normally deployed (Fig. 2B) and was presumably attached to the female's sixth sternite by means of the usual pincer action of the cuspis and digitus of the volsella. The other side of the male external genitalia was not visible, and how it was deployed or indeed whether insemination would be possible, could not be deduced.

\section{Ecological observations}

In addition to copulation behaviour, some information on the ecology of Xorides ater can be given here. First, we were interested in the altitudinal distribution of the species in Switzerland and thus obtained data from museum collections (Table 1). All 71 specimens found were collected above $980 \mathrm{~m}$ altitude, and the narrow flight time from late June to early August indicates that $X$. ater is univoltine. Furthermore, three out of the 26 collection events included at least a dozen males, while females were always only collected one or two at a time, adding support to our observation of high male abundance (Table 1).

The few and mostly unconfirmed host records that can be found for $X$. ater in the literature all include cerambycid beetles in conifers (Hilszczański 2003; Sheng and Wen 2008). The only suitably sized adult beetles seen at our site were the three species of Callidium (Coleoptera: Cerambycidae) that occur in Switzerland: Callidium aeneum De Geer, 1775, C. coriaceum Paykull, 1800, and C. violaceum Linnaeus, 1758. However, there was no direct evidence that any of these was serving as host.

While the females of $X$. ater seen were rather uniform in size, males were substantially more variable in that respect, suggesting that hosts of different sizes had been accepted, but whether of the same or different host species is unknown.

\section{Discussion}

\section{Copulatory position in $X$. ater and other Hymenoptera}

In the majority of Hymenoptera, the male genitalia are orthandrous, resulting in a mating stance whereby the male is mounted on the top of the female, the same way up and with head-to-head orientation and the apex of his metasoma curled below that of the female (Schulmeister 2001). The major exception is the Tenthredinoidea and

Table 1. Collection data from 71 individuals of Xorides ater collected in Switzerland.

\begin{tabular}{|c|c|c|c|c|c|c|c|c|}
\hline Canton. & Locality & Date & $\mathbf{N}, \mathbf{E}$ & Altitude & Males & Fem. & Legator & Collection $^{1}$ \\
\hline $\mathrm{BE}$ & Adelboden & 13 Aug.1922 & $46^{\circ} 29.54,7^{\circ} 33.35$ & 1340 & 0 & 1 & T. Steck & NMB \\
\hline GR & National park & 22 Jul.1923 & & $>1400$ & 1 & 0 & A. Barbey & MZL \\
\hline GR & National park & 26 Jul.1926 & & $>1400$ & 3 & 1 & A. Barbey & MZL \\
\hline GR & Somvix, Val Sumvitg & $25 \mathrm{Jul} .1891$ & $46^{\circ} 40.80,8^{\circ} 58.08$ & 1200 & 0 & 1 & & NMBE \\
\hline GR & Versam & 9 Jul.1898 & $46^{\circ} 47.50,9^{\circ} 19.49$ & 908 & 1 & 0 & & NMBE \\
\hline GR & Zernez, Il Fuorn & 21 Jul.1949 & $46^{\circ} 39.85,10^{\circ} 12.6$ & 1794 & 0 & 1 & J. de Beaumont & MZL \\
\hline GR & Zernez, Val dal Spöl, Praspöl & 5 Jul.1922 & $46^{\circ} 39.47,10^{\circ} 9.40$ & 1800 & 2 & 0 & C. Ferrière & $\mathrm{BNM}$ \\
\hline GR & Zernez, Val dal Spöl, Praspöl & 5 Jul.1922 & $46^{\circ} 39.47,10^{\circ} 9.40$ & 1800 & 12 & 2 & C. Ferrière & BNM \\
\hline SG & Pfäfers, Vättis & 12 Jul.1912 & $46^{\circ} 54.40,9^{\circ} 26.03$ & 980 & 0 & 1 & T. Steck & NMBE \\
\hline VS & Agettes, Les, Les Mayens-de-Sion & Aug.1946 & $46^{\circ} 12.05,7^{\circ} 22.67$ & & 0 & 1 & J.L. Nicod & MZL \\
\hline VS & Ayer, Zinal & 26 Jul.1926 & $46^{\circ} 7.94,7^{\circ} 37.19$ & 1675 & 0 & 1 & & NMBE \\
\hline VS & Champéry, Col de Bretolet & 18 Jul.1964 & $46^{\circ} 8.60,6^{\circ} 47.80$ & 1920 & 0 & 1 & & MZL \\
\hline VS & Evolène & 7 Aug.1933 & $46^{\circ} 6.33,7^{\circ} 29.42$ & 1371 & 0 & 1 & T. Steck & NMB \\
\hline VS & Evolène & 8 Jul.1911 & $46^{\circ} 6.33,7^{\circ} 29.42$ & 1371 & 1 & 0 & T. Steck & NMBE \\
\hline VS & Evolène & 7 Jul.1911 & $46^{\circ} 6.33,7^{\circ} 29.42$ & 1371 & 12 & 1 & T. Steck & NMBE \\
\hline VS & Evolène & 12 Jul.1911 & $46^{\circ} 6.33,7^{\circ} 29.42$ & 1371 & 13 & 1 & T. Steck & NMBE \\
\hline VS & Evolène, Les Haudères & 27 Jun. 1915 & $46^{\circ} 4.71,7^{\circ} 30.20$ & 1550 & 0 & 1 & T. Steck & NMB \\
\hline VS & Evolène, Les Haudères & 1 Jul.1925 & $46^{\circ} 4.71,7^{\circ} 30.20$ & 1550 & 1 & 0 & T. Steck & NMB \\
\hline VS & Grimentz & 16 Jul-5 Aug 1942 & $46^{\circ} 10.81,7^{\circ} 34.56$ & 1600 & 2 & 1 & J. de Beaumont & MZL \\
\hline VS & Grimentz & 16 Jul-5 Aug 1942 & $46^{\circ} 10.81,7^{\circ} 34.56$ & 1600 & & 1 & J.F. Aubert & MZL \\
\hline VS & Lötschental & 16 Jun.1919 & $46^{\circ} 25.18,7^{\circ} 49.73$ & 1700 & 1 & 0 & T. Steck & NMB \\
\hline VS & Saas & Jul.1938 & & & 1 & 0 & J. de Beaumont & MZL \\
\hline VS & Saas Fee & Aug.1912 & $46^{\circ} 6.27,7^{\circ} 55.03$ & 1798 & 1 & 1 & & NMB \\
\hline VS & Vissoie & 22 Jun.1921 & $46^{\circ} 12.80,7^{\circ} 34.87$ & 1200 & 0 & 1 & T. Steck & NMB \\
\hline VS & Vissoie & 24 Jun.1921 & $46^{\circ} 12.80,7^{\circ} 34.87$ & 1200 & 1 & 0 & T. Steck & NMB \\
\hline VS & Vissoie & 23 Jun.1921 & $46^{\circ} 12.80,7^{\circ} 34.87$ & 1200 & 1 & 0 & T. Steck & NMB \\
\hline
\end{tabular}

${ }^{1}$ Collection abbreviations are as follows: BNM - Bündner Naturmuseum, Chur; MZL - Musée de Zoologie, Lausanne; NMB - Natural History Museum Basel; NMBE - Natural History Museum Bern. 
Xyelinae, in which the male genitalia are strophandrous (twisted through $180^{\circ}$ ), resulting in a coplanar end-to-end stance with the two sexes looking in opposite directions (or positioned co-ventrally), as is typically seen in Lepidoptera. The database Taxapad (Yu et al. 2016) gives references to some 333 papers in which courtship and/ or mating in Ichneumonoidea is at least mentioned, but it is beyond the scope of this work to attempt a detailed review of these, and we restrict ourselves to an outline of the most usual copulatory stances seen, and a more detailed comparison between species of Xorides.

In most Ichneumonoidea, especially when the sexes are of comparable size so that the heads can be more or less adjacent, the male is usually mounted on top of the female and holds her with his legs (Fig. 3A). In this position, some degree of antennal contact during mating is usual. Indeed, the antennae of males are furnished with tyloids in species of approximately ten subfamilies of Darwin wasps (Quicke 2015), which appear to play a role in antennal communication during courtship and mating (e.g., Bin et al. 1999; Bordera and Hernandez-Rodriguez 2003; Steiner et al. 2010); an extreme example of this is seen in the diplazontine Syrphoctonus tarsatorius Panzer, 1809 (Fig. 3B; Steiner et al. 2010). In other cases, the male may slip back, foregoing antennal contact (Fig. 3C; also see Benelli et al. 2019 for the campoplgeine Campolex capitator Aubert, 1960). When the sexes are dissimilar in size, the male is usually the smaller and, because he is necessarily further back, antennal contact is often literally out of reach during copulation itself. In such cases, the male might start by climbing onto the female's back to perform antennal courtship, then sliding back as the female signals receptiveness, as we have seen in the rhyssine Rhyssa persuasoria (Fig. 3D; S. Klopfstein observations).

Once genital attachment is achieved, it seems not unusual for males, particularly in species with a large sexual size difference, to fall further back and flip through $180^{\circ}$ so that the orientation changes to one with the heads looking in opposite directions, and the male on his back with respect to the female (Fig. 2C). In such cases, there is usually little advantage in the male using many of his legs to hold onto the substrate, and they are sometimes all left free, with only his genitalia attached to anything (Suppl. material 1: Movie 1). This orientation of the male's body was seen in both of the normal copulae (Fig. 2C) and all three triplets (Fig. 2A). It has been reported also in the tryphonine subgenus Netelia (Netelia) Gray, 1860 (Vance 1927) although, in another species of the same subgenus, Shaw (2001) recorded a more normal maleon-top stance, suggesting some degree of plasticity or variation in the group. Recently, we have seen a similar stance to that encountered in $X$. ater in an unidentified species of the ophionine genus Enicospilus in Australia (Fig. 3E), though in this case the male did twist round to grasp the substrate rather than hang free.

Mating behaviour has been described for two other species of Xorides, in both cases from captive material in the laboratory. Chrystal and Skinner (1931) observed several pairings of $X$. brachylabis, noting that in courtship the male stroked the female's antennae with his own and, having approached slowly, mounted the female and grasped her with all six legs while stroking her thorax with his antennae throughout the copulation, which lasted from 15 to 40 minutes. This head-to-head alignment with the male mounted on top corresponds to our Fig. 3A. The mating behaviour of a single pair of Xorides corcyrensis described by Sharifi and Javadi (1971) differs in several respects but the male, although perhaps a little further back, was also essentially mounted head-to-head on the female. During copulation the mounted male placed his fore and mid legs on the female's mesoscutum and scutellum, with the fore legs sometimes suspended in the air.

Although unfortunately we did not witness the initiation of copulation, the position finally arrived at by $X$. ater in the copulations we observed, whether involving one or two males, differed markedly from these literature descriptions of union in other Xorides species. As in the case of Netelia mentioned above, this indicates that uniformity within a genus should not necessarily be expected. It is possible that the copulatory position of $X$. ater may be one factor facilitating matings involving two males, as more space around the female's external genitalia is exposed than in a male-on-top stance. However, additional mating observations under natural circumstances are needed to assess whether triplet-style matings are common in the genus or whether they are restricted to $X$. ater.

\section{Are triplet-style matings of adaptive significance or just a side-effect of scramble competition?}

Although males certainly predominated, we were able to find several females of $X$. ater on the woodpile that were not mating and that did not seem to attract much attention at all from the numerous males. Although they were not necessarily receptive, some females did appear freshly emerged, judging from the distended membranous separation of metasomal tergites from sternites and from particles of wood dust on them not yet cleaned away. There is thus no reason to believe that the triplet-style mating was a unique result of particularly high male density and a shortage of females, and we did not observe anything resembling scramble competition among the many males present.

Whether or not insemination was taking place in the triplets and, if so, whether it was from one or both of the males, are key questions that unfortunately we are not able to resolve at present. There are, however, several interesting considerations pertaining to this that can be briefly summarised here. If sperm transfer from both males takes place, is it a fitness strategy of the female to permit or even encourage simultaneous mating by two males, perhaps thereby ensuring a higher genetic mix for her progeny, or offsetting her risk of mating with an infertile male? By decreasing mating time while simultaneously maximising overall sperm transfer, a triplet-style mating strategy may lower the cost (for example the increased risk of predation, or simply the 

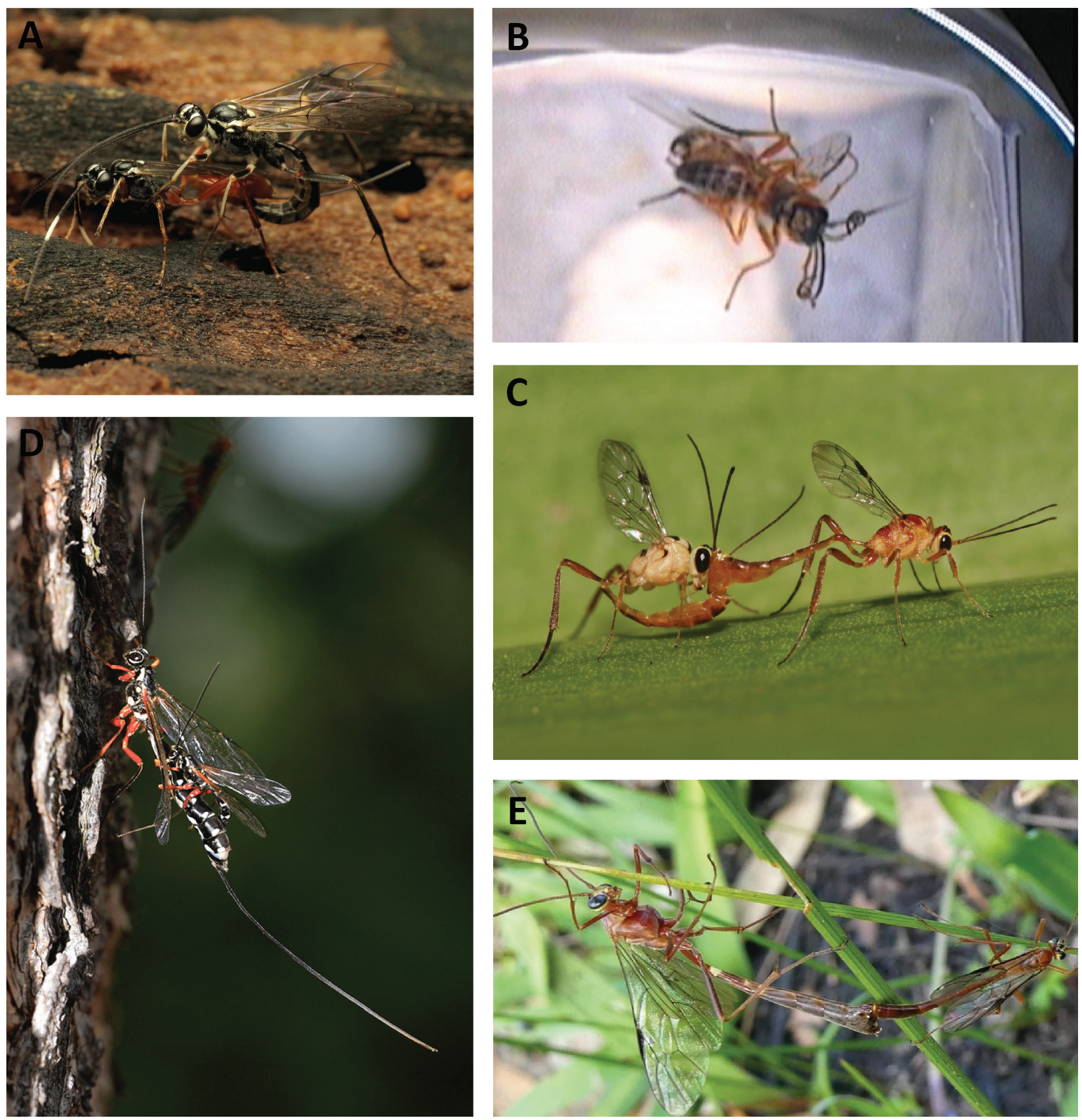

Figure 3. Various mating positions, and orthandrous attachment, of the Ichneumonidae A Cryptinae sp. exhibiting a common mating stance. Female - left, male - right. Image Credit: Katja Schulz; B Copulation in Syrphoctonus tarsatorius (Diplazontinae), with the male antennae coiled round those of the female (ventral view, taken from video sequence in Steiner et al. 2010); C Anomaloninae sp. exhibiting a common mating stance. Male - left, female - right. Image Credit: Muhammad Mahdi Kahrim; D Rhyssa persuasoria (Rhyssinae) mating pair. The significantly smaller male (right) is seen clinging to female's metasoma (left). The pair is not yet engaged in copulation. Image Credit: Reto Burri; E Enicospilus sp. (Ophioninae) in copula. Male - right, female - left. Image credit: Len van der Waag.

time investment) that would be associated with mating successively with more than one male. From the male side, is it just an unintended consequence of the scramble competition between males frequently observed in parasitoids of wood-inhabiting insects (e.g. Eggleton 1991), or is there a trade-off in avoiding conflict? Is there more than just passive sperm competition? Or, if insemination does not occur (in spite of the female's presumed belief and subsequent behaviour), and if triplet-style sterile matings are common, does it constitute a fitness impediment carried by $X$. ater by producing a higher proportion of males than would be optimal?

It would be interesting to know of additional observations of similar behaviour, whether in Xoridinae or in other ichneumonoid or hymenopteran groups. Further work is needed to elucidate whether or not sperm transfer from one or both males was successfully achieved in the triplets that evidently occur in $X$. ater at least on occasion, and possibly regularly, and any morphological modifications that might facilitate it. 


\section{Acknowledgements}

We thank Christoph Germann (Natural History Museum Basel) for identifying the Callidium beetles collected at the site, and Andrew Liston for help with literature. We also thank the Swiss National Science Foundation for funding the $20191^{\text {st }}$ International Ichneumonidae Meeting in Basel, Switzerland (under grant IZSEZ0_186618), which facilitated both the meeting and post-meeting fieldwork leading to our observations. Finally, we would like to thank Gavin Broad and Andy Bennett for their helpful suggesstions in review.

\section{References}

Baker BR (1992) Emergence and pairing of Rhyssa persuasoria L. (Hymenoptera: Ichneumonidae). British Journal of Entomology and Natural History 5: 184-185.

Benelli G, Ricciardi R, Romano D, Cosci F, Stefanini C, Lucchi A (2020) Wing-fanning frequency as a releaser boosting male mating success-High-speed video analysis of courtship behavior in Campoplex capitator, a parasitoid of Lobesia botrana. Insect science 27(6): 1298-1310. https://doi.org/10.1111/1744-7917.12740

Bennett AMR, Cardinal S, Gauld ID, Wahl DB (2019) Phylogeny of the subfamilies of Ichneumonidae (Hymenoptera). Journal of Hymenoptera Research 71: 1-156. https://doi.org/10.3897/jhr.71.32375

Bin F, Wackers F, Romani R, Isidoro N (1999) Tyloids in Pimpla turionellae (L.) are release structures of male antennal glands involved in courtship behaviour (Hymenoptera : Ichneumonidae). International Journal of Insect Morphology \& Embryology 28(1-2): 61-68. https://doi.org/10.1016/S0020-7322(99)00015-X

Bordera S, Hernandez-Rodriguez E (2003) Description of two new species of Enclisis (Hymenoptera: Ichneumonidae) and support for the secretory role of tyloids in ichneumonid males. European Journal of Entomology 100(3): 401-409. https://doi.org/10.14411/ eje.2003.062

Bredlau JP, Kester KM (2019) Evolutionary relationships of courtship songs in the parasitic wasp genus, Cotesia (Hymenoptera: Braconidae). PLoS ONE 14(1): e0210249. https://doi.org/10.1371/ journal.pone. 0210249

Chrystal RN, Skinner ER (1931) Studies in the biology of Xylonomus brachylabris $\mathrm{Kr}$., and $X$. irrigator $\mathrm{F}$., parasites of the larch longhorn beetle, Tetropium gabrieli Weise. Forestry 5: 21-331. https://doi. org/10.1093/oxfordjournals.forestry.a063207

Cole LR (1981) A visible sign of fertilisation action during oviposition by an Ichneumonid wasp, Itoplectis maculator. Animal Bahaviour 29: 299-309. https://doi.org/10.1016/S0003-3472(81)80178-9

Crozier RH (1975) Hymenoptera. In: Animal Cytogenetics Vol. 3: Insecta 7, ed. B. John, Borntraeger, Berlin, 95 pp.

Eggleton P (1991) Patterns in male mating strategies of the Rhyssini: a holophyletic group of parasitoid wasps (Hymenoptera: Ichneumonidae). Animal Behaviour 41: 829-838. https://doi. org/10.1016/S0003-3472(05)80350-1

Gauld I, Bolton B [Eds] (1988) The Hymenoptera. British Museum (Natural History) and Oxford University Press, Oxford, 322 pp.

Gerber HS, Klostermeyer EC (1970) Sex control by bees: a voluntary act of egg fertilisation during oviposition. Science 167: 83-84. https://doi.org/10.1126/science.167.3914.82
Godfray HCJ (1994) Parasitoids: Behavioural and Evolutionary Ecology. Princeton University Press, Princeton, 473 pp. https://doi. org/10.1515/9780691207025

Gravenhorst JLC (1829) Ichneumonologia Europaea, Pars III: Xorides ater. Vratislaviae Sumtibus Auctoris: 827-828. https://www. biodiversitylibrary.org/item/45179\#page/835/mode/1 up

Heimpel GE, De Boer JG (2008) Sex determination in the Hymenoptera. Annual Review of Entomology 53: 209-230. https://doi.org/10.1146/ annurev.ento.53.103106.093441

Hilszczański J (2003) Polish xoridines and their host associations. In: Melika G, Thuróczy C (Eds) Parasitic wasps: evolution, systematics, biodiversity and biological control. Agroinform, Budapest, $480 \mathrm{pp}$.

McClure M, Whistlecraft J, McNeil JN (2007) Courtship behaviour in relation to the female sex pheromone in the parasitoid, Aphidius ervi (Hymenoptera: Braconidae). Journal of Chemical Ecology 33(10): 1946-1959. https://doi.org/10.1007/s10886-007-9355-5

Klopfstein S, Langille B, Spasojevic T, Broad GR, Cooper SJB, Austin AD, Niehuis O (2019) Hybrid capture data unravels a rapid radiation of pimpliform parasitoid wasps (Hymenoptera: Ichneumonidae: Pimpliformes). Systematic Entomology 44(2): 361-383. https://doi. org/10.1111/syen.12333

Quicke DLJ (1997) Parasitic wasps. Springer, New York City, 470 pp.

Quicke DLJ (2015) The braconid and ichneumonid parasitoid wasps: biology, evolution, systematics and ecology. Wiley-Blackwell, New Jersey, 704 pp. https://doi.org/10.1002/9781118907085

Schulmeister S (2001) Functional morphology of the male genitalia and copulation in lower Hymenoptera, with special emphasis on the Tenthredinoidea s. str. (Insecta, Hymenoptera, 'Symphyta'). Acta Zoologica 82: 331-349. https://doi.org/10.1046/j.14636395.2001.00094.x

Sharifi S, Javadi J (1971) Biology of Xorides corcyrensis Kriech. (Hymenoptera: Ichneumonidae), a parasite of the Rosaceae branch borer Osphranteria coerulescens Redt. (Coleoptera: Cerambycidae). Zeitschrift für Angewandte Entomologie 68: 25-54. https://doi. org/10.1111/j.1439-0418.1971.tb03117.x

Shaw MR (2001) Interactions between adults of some species of Netelia Gray (Hymenoptera: Ichneumonidae: Tryphoninae) and their caterpillar hosts (Lepidoptera). Journal of Hymenoptera Research 10: 101-111. http://www.filming-varwild.com/articles/mark shaw/183_Netelia.pdf

Sheng ML, Wen BJ (2008) Species of Xorides (Xorides) (Hymenoptera: Ichneumonidae: Xoridinae) parasitizing wood-boring insects in the Palaearctic part of China. Entomologica Fennica 19: 86-93. https:// doi.org/10.33338/ef.84418

Steiner SM, Kropf C, Graber W, Nentwig W, Klopfstein S (2010) Antennal courtship and functional morphology of tyloids in the parasitoid wasp Syrphoctonus tarsatorius (Hymenoptera: Ichneumonidae: Diplazontinae). Arthropod Structure and Development 39: 33-40. https://doi.org/10.1016/j.asd.2009.10.001

Strand MR (1989) Oviposition behaviour and progeny allocation in the polyembryonic wasp Copidosoma floridanum (Hymenoptera; Encrytidae). Journal fo Insect Behaviour 2: 355-369. https://doi. org/10.1007/BF01068061

Vance AM (1927) On the biology of some ichneumonids of the genus Paniscus Schrk. Annals of the Entomological Society of America 20: 405-406. https://doi.org/10.1093/aesa/20.3.405

Wajnberg E, Bernstein C, Van Alphen J (2008) Behavioural ecology of insect parasitoids. Wiley-Blackwell, New Jersey, 464 pp. https://doi. org/10.1002/9780470696200 


\section{Supplementary material 1}

\section{Movie 1}

Authors: Mark R. Shaw, Madalene Giannotta, Andrés F. Herrera-Flórez, Seraina Klopfstein

Data type: multimedia

Copyright notice: This dataset is made available under the Open Database License (http://opendatacommons. org/licenses/odbl/1.0/). The Open Database License $(\mathrm{ODbL})$ is a license agreement intended to allow users to freely share, modify, and use this Dataset while maintaining this same freedom for others, provided that the original source and author(s) are credited.

Link: https://doi.org/10.3897/alpento.5.64803.suppl1

\section{Supplementary material 2}

\section{Figure S1}

Authors: Mark R. Shaw, Madalene Giannotta, Andrés F. Herrera-Flórez, Seraina Klopfstein

Data type: Raw Images

Explanation note: Two raw images used to generate the stacked composite image, Fig. 2A, in the manuscript.

Copyright notice: This dataset is made available under the Open Database License (http://opendatacommons. org/licenses/odbl/1.0/). The Open Database License $(\mathrm{ODbL})$ is a license agreement intended to allow users to freely share, modify, and use this Dataset while maintaining this same freedom for others, provided that the original source and author(s) are credited.

Link: https://doi.org/10.3897/alpento.5.64803.supp12 